\title{
FACTORS IN NON-TECHNICAL SKILLS DEVELOPMENT AMONG ENGINEERING STUDENTS: AN EMPLOYERS' PERSPECTIVE
}

\author{
Aini Najwa Azmi*,Muhammad Khair Noordin*, Yusri Kamin, Ahmad Nabil Md Nasir, Nornazira \\ Suhairom \\ School of Education, Faculty of Social Science and Humanities, Universiti Teknologi Malaysia \\ *aininajwa.azmi@gmail.com
}

\begin{abstract}
Many complaints come from employers regarding on non-technical skills among engineering graduates. Non-technical skills can be effectively developed during industrial training while they are still undergraduates. This paper is presenting the perspective of employers on factors that are developing the non-technical skills during industrial training. A qualitative study was done by interviewing five employers from electrical and electronics industries to gain the data. Thematic analysis was done after transcripting the interview protocols. The result shows that employers nowadays really need communication skills, critical thinking and problem-solving skills in an engineer. In addition, teamwork skills, lifelong learning, ethics and computing skills are the skills that are mentioned by the interviewed employers. In term of factor affecting students' non-technical skills during industrial training, they are two opinions for the first factor which is placement. Three out of five employers agreed the relevant industry to the course is crucial, but the rest disagreed. The reasons of disagreement are because the development of non-technical skills should base on the task given and the student's motivation in learning. All employers are agreed with six months duration, regular assessment, task given must be relevant with projects and presentation, and the learning outcomes must be revised regularly.
\end{abstract}

Keywords: Non-Technical Skills, Industrial Training, Engineering, Employers'Perspective

\section{INTRODUCTION}

The development of higher education and careers in the 21st century is discussed based on knowledge, skills and ability of graduates to meet industries expectations. Higher education is based on preparing a standard curriculum for students in certain period of time in order for students to be equipped by emphasizing the knowledge and specific skills (Mahmud et al., 2016). Meanwhile, the industries expectations and job market are influenced by economy, social and competition and revolutions of industry. Non-technical skill is known as the main attributes for fresh graduates to be employed by industries (Rodzalan \& Saat, 2012). The skills have changed according to the changes of era from Industry Revolution 1.0 (IR 1.0) to Industry Revolution 4.0 (IR 4.0) recently. However, certain skills remain unchanged but with a bit of enhancement to complement the needs of the today's industry.

The curriculum that is designed by Ministry of Higher Education of Malaysia should has the elements that can produce holistic graduates with technical, non-technical skills and good ethics and morality. The non-technical skills which is hard to learn in the universities can be learned effectively during industrial training (Osman et al., 2016). Industrial training is a part of university curriculum that provide an opportunity for students to apply what they have learn in the lecture class to the real workplace in the industry.

Industrial training program is in the academic curriculum in higher education institutions. This training is an opportunity for undergraduate students to incorporate work-related experience and knowledge into their formal education in a university by taking part in supervised and planned work in real-world professional environments (Renganathan et al., 2013). Industrial training program can develop students' technical skills, non-technical skills and good work ethics. Industrial training is a platform for students to gain confidence and face challenges at work such as teamwork, working under pressure and dealing with people from all levels of the organization (Pillai, 2012). Through industrial training, students can 
expose themselves to be as potential future employers, develop real workplace skills and gain a lot of work experience.

In Malaysia, the terminology of 'industrial training' is referring to "on the job training" which student is supervised by both faculty and industry supervisors. This training is one of career education in the standard curriculum to prepare university's students to make transition between campuses to career. In this study, researcher is planning to enhance industrial training components in the industrial training program as this is considered as a platform for students to improve their employability skills (Pillai, 2012). It is supposedly will be the opportunity for engineering students to expose to work environment and incorporate theories with practices. But, recently in Malaysia, there are too much concerning on the gap of competence graduates with industries expectations (Renganathan et al., 2013). The Malaysian Engineering Accreditation Council (Engineering Program Accreditation Manual, 2007) requires all bachelor's degree engineering programs to undergo at least 8 weeks of industrial training to be accredited by the council.

\section{LITERATURE REVIEW}

This section is a literature review that reports on desk-based research investigating the significant of industrial training program to increase the skills and competencies among Electrical and Electronics engineering graduates.

\section{Definition of Industrial Training Program}

This section defines the term of industrial training that is currently practice in higher learning institution in Malaysia. The terms that always used are industrial training, practical training, practicum and internship. Even though the terms are different, the meaning of the terms are like each other. On the other hand, there is not only different in terminology, the implementation, learning outcomes and scopes are different across institutions (Phang et al., 2014). Industrial training is also can be defined as a part-time job for a specific duration, modestly paid or unpaid, in which students will gain knowledge and skills in the organizations (Laguador, 2013). In addition, industrial training is a chance for students to get exposed and incorporate real workplace experience with knowledge into the formal lecture in the university (Phang et al., 2014). These can be achieved by taking part in planned and supervised professional environment.

Hands-on jobs and practical in an industry only can be done during industrial training. The laboratories in university may different with the real industry process line, which students can learn a lot in industries. Here is where student can apply all theories, knowledge and skills that they have prior training. The gaps and also similarities can be captured clearly by the students regarding to the exposure and experience in the lecture and the industry. Hence, they are able to develop their potential skills that can be used in their future career. In addition, it was consistently stated that students can get an opportunity to determine the differences in conventional learning process and real industrial process during their industrial training (Laguador, 2013). In the industry, students can practice a lot their communication skills that are very important and demanded by employer in searching a new employee (Rahim, 2016). Furthermore, industrial training is basically formed to give students hands-on training, practical knowledge and work experience in the industry. This would be a student working as an apprentice or trainee (Renganathan et al., 2013).

\section{Definition of Industrial Training Program}

Basically, the main objective of industrial training is to create an opportunity for graduating students to learn about profession, developing new and potential skills and to generate values (Laguador, 2013). Industrial training program is an important part of academic curriculum in higher learning institutions that requires all engineering students to undergo industrial training program before completing their degree. Each university has its own objectives and aims. However, the main objective is to get their students exposed to real practical knowledge in the industries. This section describes about industrial training system or procedure that are used in various public universities in Malaysia. There are a lot of differences between each university. The differences are studied to find the gap to be filled later. The discussion is based on learning outcomes, assessment, duration, placement and training. 
Moreover, many universities organise and promote the placement of industrial training in government organisations, government-link companies, private enterprises and other organizations to boost work experience so that students will attain the necessary skills to supplement their theoretical training (Mihail, 2006). Others scholars viewed industrial training as a platform to create opportunities to develop their knowledge, skills and good work ethics (Osman et al., 2016).

\section{Benefits and Learning Outcomes of Industrial Training Program}

As non-technical skills are highly demanded by employers to a new graduated employee, industrial training is suggested by scholars as a part in the formal curriculum for engineering students in developing necessary skills for employers. Industrial training can help in improving the skills that lack by the students. Based on many previous literatures, industrial training targets to exposed students into real working environment or industries (Osman et al., 2016; Renganathan et al., 2013; Phang et al., 2014). This exposure can guide student in planning their path of career and adapting well in the industry (Phang et al., 2014). In addition, students who have undergone industrial training are revealed to be more confident after graduated and start their career (Maher \& Graves, 2007). These are the reasons why industrial training is compulsory in many higher learning institution curriculums for engineering students to be graduated as stated in Engineering Accredited Council (EAC).

There are a lot of study regarding to industrial training do not identify the skills that a student needs to be a career ready graduate; most of the study focus on benefits of industrial training that can be gained from industrial training. To support this statement specifically, mentioned that engineering graduates who had their industrial training are performing better in their career comparing to who have not undergone industrial training (Kagaari, 2007). Furthermore, career entry shock can be prevented by undergoing the industrial training which is one of the industrial benefits that pointed out by. To be more precise, students can improve their personal attitudes, working attitude, communication skills and many non-technical skills after done their industrial training (Rahman et al., 2009). Thus, graduates' employability can be enhanced by undergoing industrial training. Another benefit of industrial training which is providing opportunity to strengthen the collaboration between university and industry and forming network in the professional field. Besides collaborating in research innovations and projects, these networks can hugely benefit the students in their future careers search.

\section{METHODOLOGY}

To obtain the qualitative data, purposive sampling is adopted to identify interview participants whom were included in the study. Selecting research participants according to specific qualities might increase the probability of obtaining the most relevant information to the study. In this study, qualitative part becomes important, when the interview protocol was done with experts which are experienced employers from established industries. Experts are defined as either top performers who excel in a particular field or professionals who achieve at least a moderate degree of success in their occupation. In this case, some criteria are considered:

i. At least qualified with first degree of engineering field.

ii. Senior engineer to group manager positions.

iii. Has been working in well-known or multi-national Electrical and Electronics companies or industries.

iv. Have more than 10 years experiences in industries.

v. Have experience in supervising industrial trainee or interns.

The interview protocol instrument was built by the researcher based on previous studies and modifications have been done after review from the validators. In this paper, five employers were interviewed.

\section{RESULTS AND DISCUSSION}

There are two key elements that are focused in the interview protocol. The first key element is the current needs of todays' industry in terms of non-technical skills from an engineer and the second key element is the factors that influence trainees' non-technical skills development.

\section{Current Needs of Todays' Industry in Terms of Non-Technical Skills from an Engineer}


"What are the current needs of todays' industry in terms of non-technical skills from an engineer?"

The findings to answer the above question are based on the experience of the employers from the industries with several specialization as mentioned in the previous section. The themes can be seen in Figure 1. The interviews were conducted on the employers who have the experience in training trainees or fresh engineers. All the five employers have almost similar thoughts between each other. These are the responses from the interviewee:

"The most important skill they should have is the communication skills. If the communication skill is good, all the skills can be developed easily. If you can't communicate, how the teamwork skill and problem-solving skill can develop?"

"To be an engineer, you must be firm, bold and a good decision maker. You must be responsible to what you are doing."

"Communication in English is important, but it becomes less important if you are working in the government sector, local company or eastern company"

(Employer 1)

"The first one is definitely communication skill. A lot of the new engineers are shy, and they are not able to speak up their thoughts. They may be brilliant, but if they don't know how to speak, their thoughts cannot be delivered"

"An engineer must have their own responsibility even though the task is given in a group. For me, I love to give personal task as it shows the real performance of an engineer"

"Giving new ideas or arguing other people ideas are good. This is what I want from my engineers."

(Employer 2)

"An engineer should know how to communicate with abroad customers or supplier"

"An engineer should play a significant role in a team while handling a project."

"I want my engineer to be an innovative person. Solve a problem like we will never face the same problem again."

"An engineer must eager to learn new knowledge and then apply it."

(Employer 3)

"For me, computing skills is important if you are working in the company I work. It is including programming and scripting skills. "

"Even though some tasks are more individual, but the engineers must know how to approach colleague and ask if any problem occurs. They must know how to socialize."

"Meeting deadline is very important for engineer to take care of. That is why if they don't know how to solve a task, they must find a way to solve it. In the company that I work, new engineer will be attached to the senior engineer, and we called it "Buddy System". The new engineer will be guide accordingly for 6 months of time."

(Employer 4)

"An engineer is a problem solver. So, problem solving skill is the most important. He/she must be a fast-learner"

"The culture of the company I work, the engineer must learn together with his/her partner. Thus, the engineers must have good communication skill. Why? Because they need to approach their colleague 
or supervisor to ask. Furthermore, communication in English language is very important either verbally or written. They also need to do many presentations in the meeting and also to their boss."

(Employer 5)

By looking to the responses from the employers, all of them are agree on the importance of the communication skills. Communication in English language is essential when entering the working world. Employers 4 and 5 agreed that they must have a good communication skill as they need to socialize with another colleague. Besides, Employer 3 said that the essential of communication skill is when the engineers need to handle abroad customers and suppliers.

Critical thinking and problem-solving skills are also important as engineers are the problem-solvers as mentioned by Employer 5. Furthermore, engineers should responsible on what they are doing and play significant role in a team project. This is agreed by all the employers. In addition, all employers agreed that decision making skill is important and an engineer must know how to speak up new ideas or argue other people ideas.

Lifelong learning is one of the skills that are needed in today's industry. All employers want engineers which are independent and eager to learn new knowledge and fast-learners.

\section{The Factors that Influence Trainees' Non-Technical Skills Development}

"What are the factors that influence them to improve trainees' non-technical skills?"

There are five components in the above question were being asked namely placement of the industrial training, training duration, assessment, training and learning outcomes. The themes can be seen in Figure 2. Like the previous key element, the findings are based on the experience of the employers from the industries with several specialization as mentioned in the previous section. The interviews were conducted on the employers who have the experience in training trainees or fresh engineers. All the five employers have almost similar thoughts between each other. These are the responses from the interviewee:

"Placement is not too crucial. What's important is job scope given to the trainee which is suitable to the level of what they will be in the future which are the engineers"

"For me, the best duration is 6 months. Why? Because they need time to know, to learn, to understand and to apply."

"I think, a standard evaluation from industry is essential. The form from the university is also important because the learning outcomes are set by the university. But the feedback from the industry is the most important and can be analyzed by university for future action."

"The task given should be the engineer tasks such as mini projects and the trainee must go for presentation. This can definitely develop her/his communication skill."

"Learning outcomes must base on industries feedback."

Employer 1

"Placement in the industry is very important. Because the trainees will get relevant task while they undergo industrial training. This can develop their soft-skill effectively"

"I agree if they go for 6 months. 6 months is not long if you want to sample it to the total years you will be serve as engineer. For me 8-12 weeks is not enough for them to gain skills. It just a condition for them to pass the industrial training."

"Regular assessment is important to observe the progress of the trainee from time to time. Weekly basis is good."

"Solving problems in a project, enter management board meeting and operational meeting every morning. Project is bigger. In a project, there are many problems." 


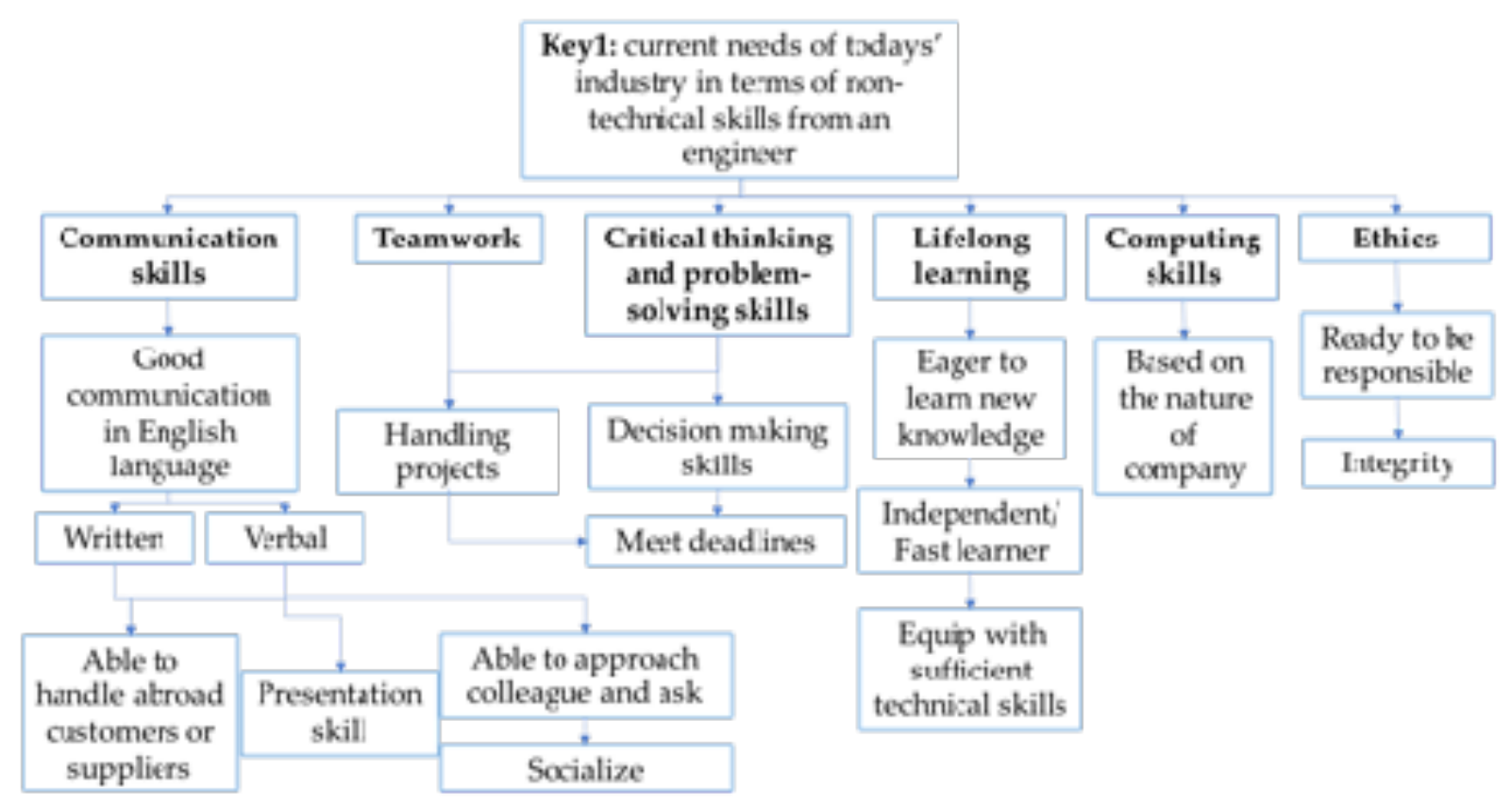

Figure 1. Themes of interview for the current needs of todays' industry in terms of non-technical skills from an engineer 


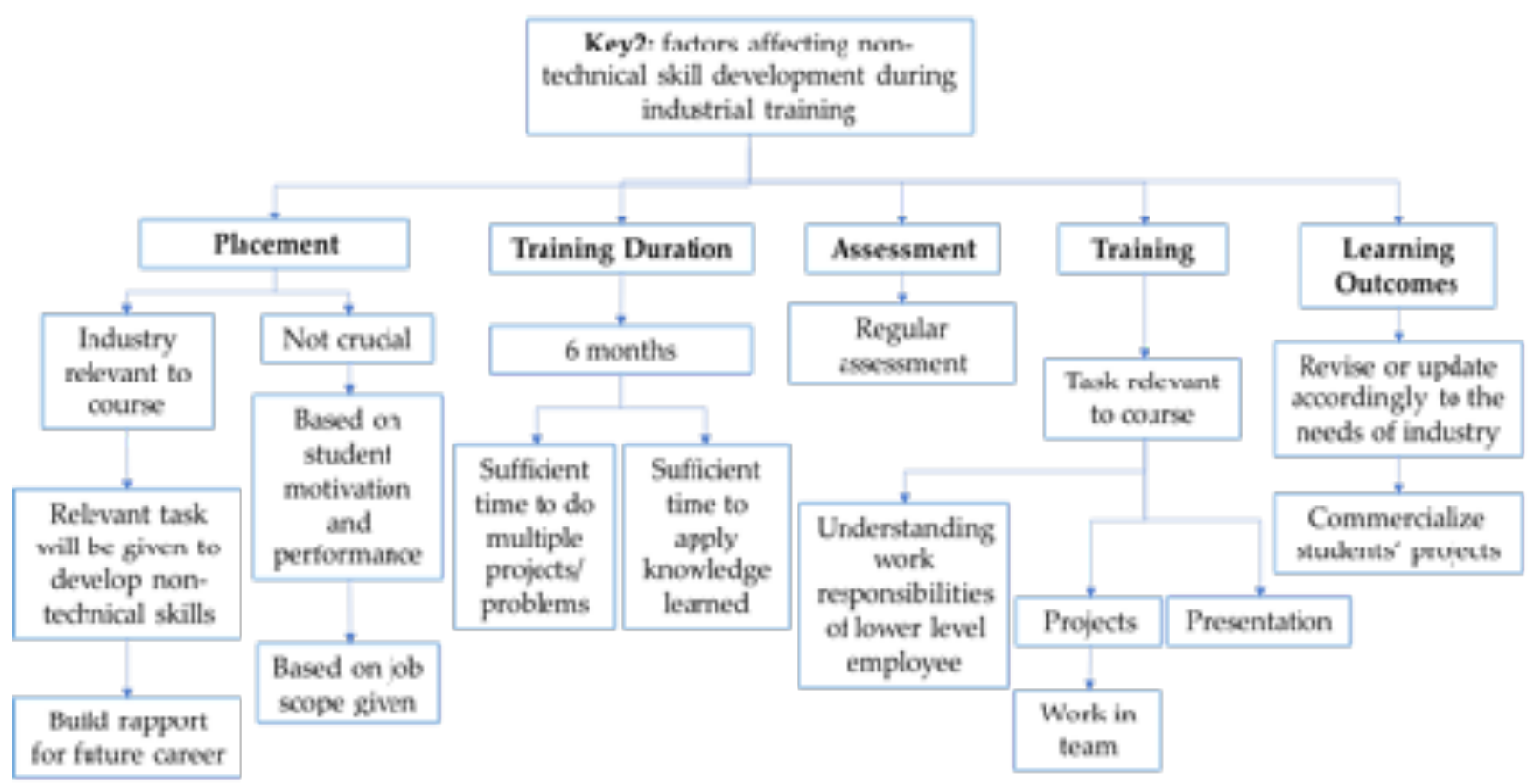

Figure 2. Themes of interview for the factors that influence trainees' non-technical skills development

"Relevant industry to the program is very important. Trainees should give their full effort while training and build networking. This is important for their future career."

"In my opinion, regardless of 2-3 months or longer duration, the students should motivate themselves to learn as much as they can. But, for me, the industries need 6 months to help the trainee to gain as much as possible. The time is enough for them to settle multiple projects and to build some rapport for future career."

"Project is given to them in team. While working in team, many soft-skills can be learned."

Employer 3

"I really don't think the type of industry is important for industrial trainees to develop their soft-skills. If technical skills, then it will be yes!"

"Trainee should not complaint if they are being assigned cheap labour tasks. As engineer, understanding work responsibilities of low level employee is very important."

"The networking or linkage with the industries can help university to commercialize students' projects. This can be added in the learning outcomes."

Employer 4

"The trainee must go to relevant industry. If not, the task given is also not relevant. If they know nothing about what they will done, not only the technical skill hard to be developed, the soft-skill hard to be developed as well."

"6 months is the minimum. If less than that, they cannot learn much."

"Recognition from employer to the excellent performance of trainee can be done to motivate the trainee more."

Employer 5

Based on the responses above, Employers 1 and 4 did not think the placement of industrial training in 
the industries is very important. They thought that the trainees should be motivated to perform in any industry. The most important is the appropriate job scope or type of task given to the trainees.

It can be seen clearly that all employers agree with 6 months of industrial training for engineering students. Their reasons are students will have enough time to do multiple projects and they have more time to build rapport with the industry as it is very important for their future career after graduated.

Many employers are agreed with regular assessment to the trainees to make sure they are progressed based on the task given. The trainees should not be neglected because they need a lot of attention during industrial training as industry is the first place for them in the real environment for professional engineers.

Furthermore, tasks given or type of training to the trainee that should involve are projects or mini projects which always be given in a team. Employer 4 has said that the trainees should not complaint if the lower-level task is given, but they should have the understanding on work responsibilities of lowerlevel employees. This understanding is important to solve any problems that involve operation. In addition, trainees must learn how to do presentation. This is the golden chance for trainees to improve themselves in communication skill.

Learning outcomes for the industrial training that are set by the university are very important as guide for the university and industries on what students need to achieve after underwent the training. As suggested by all interviewed employers, university need to revise or update the learning outcomes accordingly based on the needs of industries.

\section{CONCLUSION}

Non-technical skills include problem solving, communication skill especially in English, able to work in team, high self-esteem and more. Many previous researchers reported that fresh graduates are always lack of these non-technical skills (Muhammad Khair et al., 2016). This will be a very huge challenge to public universities in Malaysia in preparing a standard curriculum to produce graduates with appropriate non-technical skills to undergo employment in the industries. Furthermore, success cannot be guaranteed by solely depending on technical skills since an engineer needs to possess a good set of non- technical skills as well (Rasul, Rose \& Mansor, 2013). Thus, it is important for engineering graduates to equip themselves with enough non-technical skills to complement their technical skills.

Entering the professional workplace in the industries, "employers seek graduate employees who are able to transfer their critical thinking abilities to the workplace" (Phang et al., 2014; Laguador, 2013). This is the proof that critical thinking that lead to problem solving skill is very important. However, not all fresh engineering graduates in Malaysia can possessed this skill outstandingly. Based on a research done (Husain et al., 2013), critical thinking and problem solving skills are at the below of the ranking compared to teamwork skill which is in the first ranking. Critical thinking and problemsolving skills should be emphasized by higher institution because these skills are demanded by today's industry. Furthermore, students feel that their critical thinking and problem solving skills are good, but the employers in the industries feel that their non-technical skills are at the intermediate level (Husain et al., 2013). The gap between students' and employers' perception will give an impending problem for fresh engineering graduates to be hired once they are graduated. An employee who is high in critical thinking and problem-solving skills according to the employers could demonstrate creative and innovative thinking, able to generate new ideas and able to decide the best alternative.

Duration of the training is the issue has been discussed in many previous studies. For example, based on a study done by Phang et al. (2014), employers suggested that industrial training for engineering students should be six months. This statement supports the findings in this paper. Thus, due to the differences of perception of the duration for the training, it is rational to look at it based on the standard period to accomplish all the intended outcomes of the training. 
As non-technical skills are highly demanded by employers to a new graduated employee, industrial training is suggested by scholars as a part in the formal curriculum for engineering students in developing necessary skills for employers. Industrial training can help in improving the skills that lack by the students. Based on many previous literatures, industrial training targets to exposed students into real working environment or industries (Osman et al., 2016; Renganathan et al., 2013). This exposure can guide student in planning their path of career and adapting well in the industry (Phang et al., 2014). In addition, students who have undergone industrial training are revealed to be more confident after graduated and start their career (Maher \& Graves, 2007). These are the reasons why industrial training is compulsory in many higher learning institution curriculums for engineering students to be graduated as stated in Engineering Accredited Council (EAC).

\section{ACKNOWLEDGEMENTS}

We would like to thank School of Graduate Studies (SPS), UTM for assisting this study financially through Zamalah Scholarship.

\section{REFERENCES}

Ab Rahman, M. N., Omar, M. Z., Kofli, N. T., Mat, K., Osman, S. A., \& Darus, Z. M. (2009). Assessment of engineering students perception after industrial training placement. European Journal of Social Sciences, 8(3), 420-431.

Husain, M. Y., Rasul, M. S., Mustapha, R., Malik, S. A., \& Rauf, R. A. A. (2013). Tahap kemahiran employability pelajar kejuruteraan dari perspektif majikan. Sains Humanika, 62(1), 31-39.

Kagaari, J. R. (2007). Evaluation of the effects of vocational choice and practical training on students' employability. Journal of European Industrial Training, 31(6), 449-471.

Noordin, M. K., Ismail, S., Ali, D. F., Nasir, A. N. M., \& Nordin, M. S. (2016). Framework for ProjectBased Learning (PjBL) in providing real world experience for electrical engineering students. https:// www.researchgate.net/profile/Muhammad_Khair_Noordin/publication/

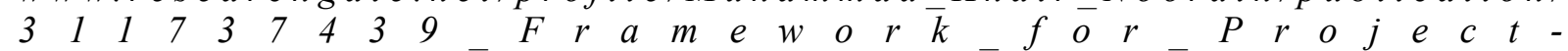
Based_Learning_PjBL_in_Providing_Real_World_Experience_for_Electricäl_Engineering_Students/

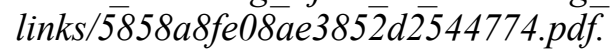

Laguador, J. M. (2013). Engineering students' academic and on-the-job training performance appraisal analysis. International Journal of e-Education, e-Business, e-Management and eLearning, 3(4), 301-305.

Maher, A., \& Graves, S. (2007). Making students more employable: Can higher education deliver. In Euro CHRIE Conference, pp. 1-9.

Mahmud, M. I., Noah, S. M., Ahmad, J., \& Ahmad, W. M. W. (2017). Modul kesediaan kerjaya berdasarkan teori Cognitive Information Processing (CIP). JuKu: Jurnal Kurikulum \& Pengajaran Asia Pasifik, 4(3), 59-76.

Mihail, D. M. (2006). Internships at Greek universities: An exploratory study. Journal of Workplace Learning, 18(1), 28-41.

Osman, S. A., Khoiry, M. A., Rahman, N. A., Rahni, A. A. A., Mansor, M. R. A., Nordin, D., \& Johar, S. (2016). The effectiveness of industrial training from the perspective of students of the civil and structure engineering department. Journal of Engineering Science and Technology, 11, 1-12.

Phang, F. A., Yusof, K. M., Saat, M. M., \& Yusof, N. M. (2014). Perceptions of engineering students on industrial training in Malaysia. In QScience Proceedings (World Congress on Engineering Education), pp. 1-6.

Pillai, S., Khan, M. H., Ibrahim, I. S., \& Raphael, S. (2012). Enhancing employability through industrial training in the Malaysian context. Higher Education, 63(2), 187-204.

Rahim, H. L., \& Lajin, N. F. M. (2015). Social entrepreneurship and graduate employability. International Academic Research Journal of Social Science, 1(1), 33-40.

Rasul, M. S., \& Mansor, A. N. (2013). Employability skills indicator as perceived by manufacturing employers. Asian Social Science, 9(8), 42-46.

Renganathan, S., Ambri Bin Abdul Karim, Z., \& Su Li, C. (2012). Students' perception of industrial internship programme. Education+ Training, 54(2/3), 180-191.

Rodzalan, S. A., \& Saat, M. M. (2012). The effects of industrial training on students' generic skills development. Procedia-social and behavioral sciences, 56, 357-368. 